\title{
A survey of the evolution of remote sensing imaging systems and urban remote sensing applications
}

Book or Report Section

Accepted Version

Fugate, D., Tarnavsky, E. and Stow, D. (2010) A survey of the evolution of remote sensing imaging systems and urban remote sensing applications. In: Rashed, T. and Jürgens, C. (eds.) Remote Sensing of Urban and Suburban Areas. Remote Sensing and Digital Image Processing, 10. Springer, Dordrecht, pp. 119-139. ISBN 9781402043710 doi: https://doi.org/10.1007/978-1-4020-4385-7_7 Available at http://centaur.reading.ac.uk/95192/

It is advisable to refer to the publisher's version if you intend to cite from the work. See Guidance on citing.

To link to this article DOI: http://dx.doi.org/10.1007/978-1-4020-4385-7_7

Publisher: Springer

All outputs in CentAUR are protected by Intellectual Property Rights law, 
including copyright law. Copyright and IPR is retained by the creators or other copyright holders. Terms and conditions for use of this material are defined in the End User Agreement.

\section{www.reading.ac.uk/centaur}

\section{CentAUR}

Central Archive at the University of Reading

Reading's research outputs online 


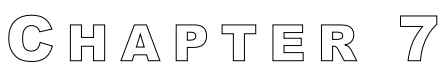

\section{A SuRVEy OF the EVOLUtion OF Satellite Based Remote Sensing IMAGING SYSTEMS AND URBAN Remote Sensing Applications}

\section{Debbie Fugate, Elena Tarnavsky, and Douglas Stow}

$\mathrm{T}$

he focus of this chapter is on the development of satellite based remote sensing imaging systems and their contribution to the evolution of urban remote sensing. A chronological overview of remote sensing. applications is also provided, emphasizing key trends in urban

\begin{tabular}{c}
\hline \hline L E A R N I N G O B J E C T I V E S \\
Upon completion of this chapter, the student should gain an \\
understanding of the following key concepts: \\
The increasingly diverse nature of sensor \\
systems and imagery products, as well as their \\
commercial availability, have led to a broad set \\
of urban remote sensing applications. \\
Technological advances in imaging sensor \\
capabilities have contributed to the increased \\
breadth and depth of urban remote sensing \\
applications, resulting in rich, interdisciplinary \\
topics that come under the umbrella of urban \\
remote sensing. \\
$\begin{array}{l}\text { The complexity and dynamics of urban } \\
\text { environments present a unique challenge to the } \\
\text { remote sensing research community. } \\
\text { Confronting this challenge in an interdisciplinary } \\
\text { manner has given rise to the pursuit of novel } \\
\text { approaches to the study of urban environments. }\end{array}$ \\
\hline \hline
\end{tabular}

\subsection{INTRODUCTION}

The variety of remote sensing imaging systems and urban remote sensing applications is due in part to the reciprocal exchange of expertise 
between the domains of information technology and an emergent interest in the structural complexity and dynamics of urban environments. Remote sensing is a discipline encompassing a wide array of applications. Broader and increasingly interdisciplinary applications are driven by the evolving technological characteristics of remote-sensing systems, increased availability of remotely sensed imagery, and advances in data processing and analysis techniques. These drivers have inspired new thinking about the urban environment that provided the impetus for urban remote sensing.

In this chapter, the evolution of applications is traced, as driven by technological developments of imaging instruments and ensuing availability and access to remotely sensed imagery. The focus is on satellite systems that have been most commonly used for urban analyses. Through a chronological overview of applications, the development of urban remote sensing is outlined from the early days of aerial photography to recent advances in satellite imaging and image processing technologies. Finally, the chapter concludes with a summary of key trends in the joint evolution of remote sensing systems and urban remote sensing applications.

\subsection{Evolution of Satellite Based Remote Sensing Systems}

Urban environments are characterized by complex and dynamic biophysical and socio-economic attributes continuously varying across space and time. The ability to map, monitor, and analyze such attributes from remotely sensed imagery greatly depends on the characteristics of the imaging instruments. Remote sensing instruments include photographic (film-based cameras) and non-photographic sensor systems (radiometers, digital cameras, radar systems, and electro-optical scanners).

The great variety of satellite based remote sensing systems that are currently operational are often designed for specific earth observation missions and thus, have different operational principles and technical characteristics. The focus here is on imaging systems mounted on earth orbiting satellite platforms, designed to collect imagery of the earth surface at regular time intervals. Airborne imaging systems have been commonly used in the early years of urban remote sensing, but their technical characteristics are not discussed here. Jensen (1996) provides a more detailed review of airborne imaging systems' characteristics. The following major imaging satellites will be covered in this chapter:

- Landsat (originally called Earth Resources Technology Satellite or ERTS) developed by National Aeronautics and Space Administration (NASA) and operated by the United States Geological Survey (USGS), 
- the French earth observing series of satellites called Satellite Pour l'Observation de la Terre (SPOT),

- Indian Remote Sensing (IRS) operated by the Indian government,

- the U.S. Defense Meteorological Satellite Program (DMSP) series,

- IKONOS by Space Imaging, Inc.,

- the ASTER imaging system mounted on the TERRA earth observing satellite and operated by NASA, and

- the QuickBird mission by Digital Globe (f.k.a. Earth Watch, Inc).

The first successful launch year for each of the above missions is marked in Figure 7.1 to illustrate their operational duration.

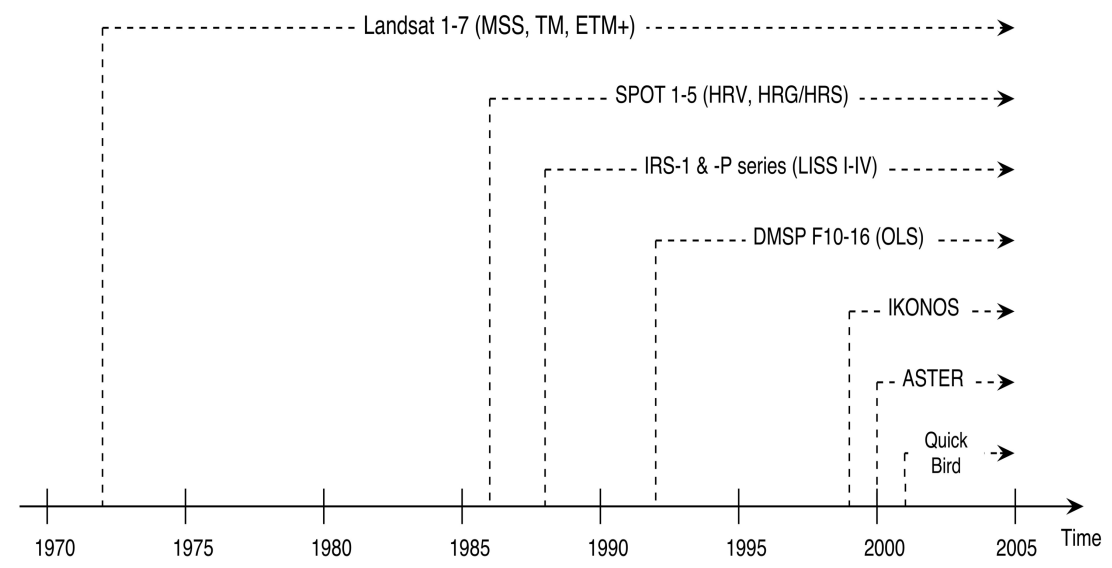

Fig 7. 1. Duration of operational satellite based earth observing missions most commonly used in urban remote sensing applications.

Although the operating principles of various imaging instruments have changed over the years, the spectrum of applications and usability of imagery have been largely determined by the spatial, radiometric, spectral, and temporal resolutions of the imaging system. Image resolutions play a major role in determining the size and properties of the features or phenomena that can be discriminated in remotely sensed imagery and thus, allow researchers and practitioners to make inferences and decisions with regard to the usability of specific imagery. The spatial, radiometric, spectral, and temporal resolutions are discussed below for the digital imaging systems and multi-spectral scanners listed in Figure 7.1. Spatial, radiometric, spectral, and temporal resolutions can each be defined in two different contexts, the users' needs and the technical specifications of the imaging system. In the context of users' needs, definitions usually refer to resolutions needed for a particular study. Of 
greater emphasis here are definitions of spatial, radiometric, spectral, and temporal resolutions referring to the imaging sensor characteristics.

While the emphasis in this section is on the resolution or precision of remotely sensed measurements, the reader should be aware that the extent, duration, or location of the measurement in space, time, and spectral or energy intervals may be equally as important. For instance, the spatial extent of coverage, range of energy levels sensed, position of wavebands throughout the spectrum, or temporal record length of archived imagery are also important factors when selecting imagery to match a particular urban application.

\subsubsection{Spatial Resolution}

The spatial resolution of remote sensing instruments is a function of the altitude of the platform relative to the earth surface and the resolving power of the sensor, and is often expressed as the ground sampling distance (GSD) of the sensor at nadir. High spatial resolution imagery provides a closer view of smaller objects and low spatial resolution imagery provides a farther view of larger objects.

Moderate to high spatial resolution imagery has been used for urban remote sensing applications. Imagery at $80 \mathrm{~m}$ spatial resolution has been available from the Landsat MSS archive since 1972, and at $30 \mathrm{~m}$ since the mid 1980's, from the Landsat TM sensor. In the late 1980s, the French Centre National d'Etudes Spatiales (CNES) launched the SPOT mission with the first four satellites carrying the High Resolution Visible (HRV) payload acquiring images of $10 \mathrm{~m}$ resolution in panchromatic mode and $20 \mathrm{~m}$ resolution in visible/near infrared (V/NIR) mode. On May 4, 2002 SPOT 5 was launched with two different payloads, the High Resolution Geometric (HRG) panchromatic instrument and the High Resolution Stereoscopic (HRS) multispectral sensor with spatial resolutions of $2.5 \mathrm{~m}$ and $10 \mathrm{~m}$, respectively. In addition to the higher spatial resolution than the HRV, the HRS includes a shortwave infrared (SWIR) band. The Indian Department of Space launched a series of IRS satellites equipped with high and moderate spatial resolution versions of the Linear Imaging Spectral Scanner (LISS). The latest IRS RESOURCESAT-1 satellite was launched on October 17, 2003 and provides imagery from three spaceborne sensors, the high resolution LISS sensor (LISS-IV), the medium resolution LISS sensor (LISS-III), and the Advanced Wide Field Sensor (AWiFS) with spatial resolutions of $6 \mathrm{~m}$, $24 \mathrm{~m}$, and $60 \mathrm{~m}$, respectively (Rao and Cook, 2004). RESOURCESAT-2 is planned for launch in 2006 and will carry the high spatial resolution version of the LISS payload.

Since 1999 the urban remote sensing community has had access to imagery from very high spatial resolution sensors such as the digital 
imaging payloads onboard IKONOS and Digital Globe's QuickBird satellite system. Although IKONOS 1 and QuickBird 1 both experienced launch failures, the second missions launched in the end of 1999 and 2000, respectively, are currently operational. IKONOS and QuickBird provide images at $1 \mathrm{~m}$ and $0.6 \mathrm{~cm}$ spatial resolution in panchromatic mode and $4 \mathrm{~m}$ and $2.5 \mathrm{~m}$ spatial resolution in V/NIR mode. The OrbView3 satellite system was launched in 2003 and has similar sensor specifications as the IKONOS system. A new IRS mission (CartoSat) designed for cartographic applications is planned for launch in 2004 and will provide panchromatic imagery at $2.5 \mathrm{~m}$.

Urban remote sensing applications have substantially benefited from the high spatial resolution characteristics of commercial satellite image data and the ensuing ability to monitor smaller features of interest in complex urban environments (Donnay et al., 2001). The trend of increasing spatial resolution of imaging sensors since the 1970's is illustrated in Figure 7.2 and includes all satellite imaging systems of pertinence.

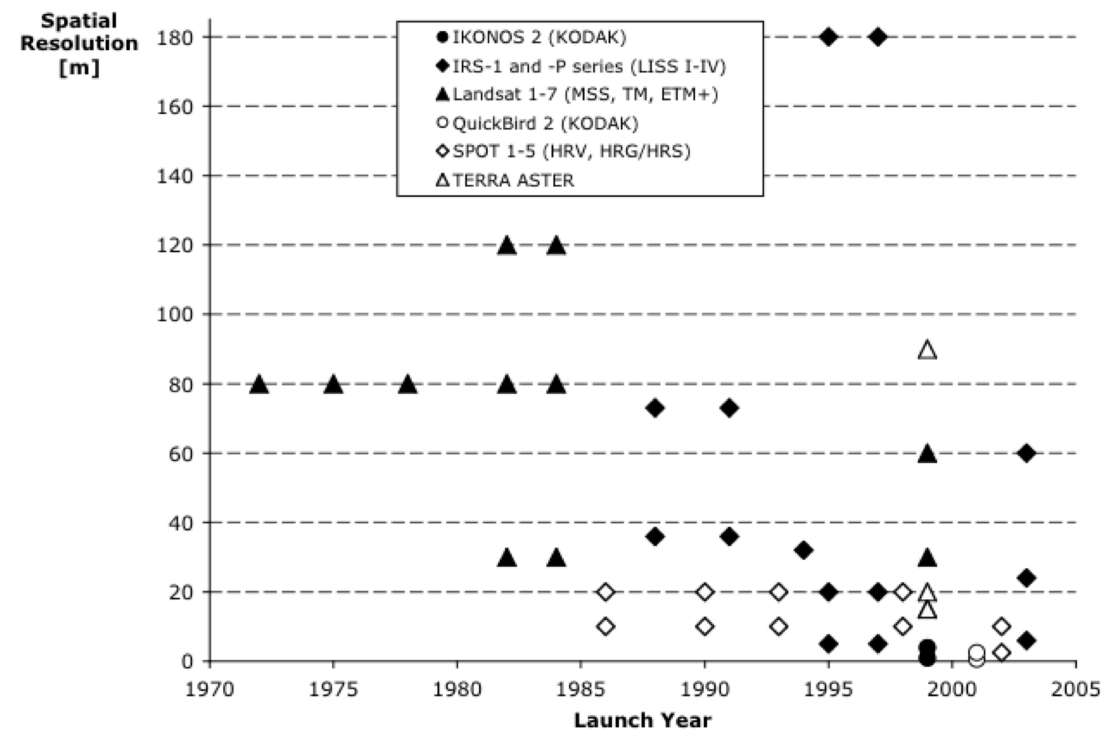

Fig 7.2. Historical trend of increasing spatial resolution of satellite based imaging systems most commonly used in urban remote sensing applications. The DMSP Operational Linescan System (OLS) is not included in the figure due to its relatively low spatial resolution at $2.7 \mathrm{~km}$ low spatial resolution (smooth mode) and at $550 \mathrm{~m}$ high spatial resolution (fine mode) (Dickinson et al., 1974). 


\subsubsection{Radiometric Resolution}

The radiometric resolution (or radiometric precision) of remote sensing data is determined by the detector or film sensitivity and noise level, as well as the quantitative manner in which analog radiance measurements are digitized and stored as digital number (DN) values (called the quantization level). The detector-related effects are often characterized as the noise equivalent difference in radiance $(\mathrm{NE} \Delta \mathrm{L})$ or reflectance $(\mathrm{NE} \Delta \rho)$. Since the recorded digital number is a discrete quantified measure of the originally continuous radiance measurement (i.e. the energy received at the sensor), the greater the quantization level the closer the quantized image output approximates the original continuous data (Schowengerdt, 1997). Generally, quantization levels for most systems range between 8 -bits (256 gray levels) and 12-bits (4,096 gray levels).

Successful
analysis of
remotely sensed
imagery is
dependent on
sufficient
radiometric
resolution.

Suitable radiometric resolution is achieved when the $\mathrm{NE} \Delta \mathrm{L}$ is sufficiently low and the quantization level high enough to allow discrimination among the reflected or emitted energy levels recorded for various phenomena of interest in urban environments. Conversely, low radiometric resolution (such as 6-bit quantization level) can be prone to saturation, impeding discrimination of urban environment features due to insufficient contrast (Jensen and Cowen, 1999). The first spaceborne imaging systems, such as the Landsat Multispectral Scanner (MSS), used a 6-bit quantization level. Similarly, some of the earlier IRS platform payloads output images at 7-bit quantization level, while other IRS series record images at 8-bit and 16-bit quantization levels. The quantization level of most imaging systems (Landsat TM and ETM+, SPOT, DMSP, IKONOS, ASTER, and QuickBird) is generally between 8-bit and 12-bit.

\subsubsection{Spectral Resolution}

The historical trend in the evolution of imaging systems has been toward increased spectral sensitivity.
Spectral resolution refers to the capability of an imaging system to measure and record sensed radiation within discrete ranges of wavelengths (referred to as wavebands). The importance of spectral resolution in urban remote sensing analyses is discussed in detail by Herold et al. (2004). The historical trend in the evolution of imaging systems has been toward increased spectral sensitivity, i.e. greater number of bands and narrower wavelength ranges. 
Imaging spectrometers or hyperspectral imagers are capable of sensing hundreds of narrow wavebands across the UV, visible, NIR, SWIR, and TIR portions of the spectrum. The only civilian spaceborne imaging spectrometer has been the Hyperion instrument on the NASA EO-1 satellite. However, a number of airborne imaging spectrometers have and continue to acquire hyperspectral image data. The key advantage of hyperspectral image data (c. $10 \mathrm{~nm}$ spectral resolution) over broadband multispectral data (c. $100 \mathrm{~nm}$ spectral resolution) is the ability to select specific and multiple narrow wavebands that optimally discriminate urban surface materials or quantify urban surface conditions.

\subsubsection{Temporal Resolution}

The temporal resolution of a remote sensing system can be defined as either the theoretical or operational capability for acquiring repetitive imagery over some time interval. Platform characteristics are the primary factors influencing the theoretical temporal resolution. Aircraft are more mobile than spacecraft platforms and provide the potential for temporal resolutions of a few minutes (seconds for rotary-wing aircraft). Most spaceborne systems utilize polar-orbiting satellites, with limited repeat potential from several days to a few weeks. The spatial extent of images depends on the swath width and influences the resulting temporal resolution. Larger viewing swath widths allow for monitoring of the Earth's surface in shorter time periods and thus, shorter revisit intervals. Equatorial-orbiting, geo-stationary satellites have the potential for nearly continuous imaging (i.e., infinitely fine temporal resolution). Operationally, even polar-orbiting satellites tend to achieve higher temporal resolution than airborne systems, because of their regular orbits and systematic data collection and archiving capabilities. Also, the pointability of many newer generation satellite sensors enables higher temporal resolution for polar-orbiting satellites that would normally have a long repeat interval.

In the early 1970's temporal resolution tended to vary inversely with spatial resolution. The closer the platform is to the earth surface (i.e., lower the orbit), the higher the spatial resolution and the lower spatial coverage and therefore, the temporal resolution. This relationship is valid for scanning radiometers (such as the Landsat Thematic Mapper) designed to collect images over a fixed swath width centered at nadir. However, as discussed previously, with the advent of pointable imaging sensors such as SPOT, IKONOS, and Quickbird, that can capture imagery off-nadir while orbiting the earth, temporal resolutions have been reduced. 


\subsubsection{Selection of Appropriate Resolutions}

Given the complexity of urban environments and the high spatial

Resolution requirements are determined by the nature and goals of the study at hand. heterogeneity of urban materials, spatial, radiometric, and spectral resolution should be specified together, with the objective of achieving highest possible separability of features of interest. Note that it is not possible to fully optimize spectral, radiometric, and spatial resolution for a given instrument. High separability is achieved through proper selection of resolutions according to the level of detail targeted in the information extraction process in a particular study. Spatial properties of features may lead to the use of techniques that also incorporate their spectral properties. Features of interest may be represented as part of a single pixel in a coarse spatial resolution image, thus resulting in spectral mixing of multiple land cover materials in a single image pixel and the use of spectral unmixing models. Similarly, features or objects of interest may be represented as multiple pixels in high spatial resolution imagery. Thus, proper selection of spectral and spatial resolutions can facilitate the ability to extract information from imagery at the necessary level of detail.

Selection of the most appropriate or optimal image spatial and spectral resolutions should be based on the image processing and interpretation approach to be utilized. If visual interpretation and manual mapping techniques are to be employed, then the highest spatial resolution imagery available should generally be chosen. Extraneous detail is normally filtered or ignored through the human cognitive element of visual interpretation. Of course, areal coverage and cost considerations may need to be traded-off with high spatial resolution, when making such a choice. If semi-automated, per-pixel image classification approaches are to be implemented, then moderate resolution imagery (e.g., SPOT HRV or Landsat TM) may provide superior land use and land cover mapping results for urban and urbanizing areas, relative to high spatial resolution image data (Chen et al, in press). Conversely, land use and land cover classification or linear feature (e.g., road) extraction based primarily on texture measures will tend to yield superior results when derived from high spatial resolution image data (Chen and Stow, 2002).

Although there is an apparent need for careful selection of resolution characteristics according to the nature and goals of urban studies, there is no unanimous agreement on the sole importance of a specific resolution characteristic for selection of suitable imagery. Some researchers have observed that spatial resolution has generally been the single most important technical characteristic for urban remote sensing applications (Welch, 1982). However, Jensen and Cowen (1999) 
discussed a rating system for determining the usefulness of imagery that emphasized the importance of other technical characteristics and argued that spatial resolution alone cannot determine the usefulness of imagery. While higher resolution generally means greater resolving ability in the spatial, radiometric, spectral, or temporal domains, requirements such as storage, processing time, and data exchange should be taken into account, especially if these are the limiting factors.

\subsection{Early URban Remote Sensing, 1950-1970}

The following section presents a chronological overview of urban remote sensing applications from 1950-1970. This is primarily a review of typical applications that utilized film-based systems (prior to the launch of the Landsat satellites), and were dominated by studies of urban and infrastructure development.

Studies of urban places using remotely sensed data can be found in the journal of Photogrammetric Engineering (now titled Photogrammetric Engineering and Remote Sensing) as far back as the second volume published in 1936. An annotated bibliography compiled by Chardon and Schwertz (1972) and leading remote sensing journals reveals the following information pertaining to urban remote sensing.

During the 1950-1970 period, remote sensing researchers concerned with urban applications mostly published results from exploratory analysis of the potential of airborne remote sensing for the study of urban environments and specific urban area problems. The three key areas of interest were: (1) urban land use and dynamics of the residential and industrial components (starting as early as in the 1950's), (2) mapping, analysis, and planning of the urban transportation infrastructure (late 1950's), and (3) mapping density and quality, of housing units, including environmental health conditions (starting as early as 1960's).

Geographical areas of interest during the 1950-1970 period varied considerably. Within the United States Los Angeles and Phoenix appear to have been studied more often than other cities, with the objective of determining pollution levels and urban growth boundaries from remotely sensed imagery. In the early urban remote sensing period, mostly filmbased cameras (using black and white, color, or color infrared film) were used to collect aerial photographs, but some studies used video and multi-spectral digital cameras. Radar, image spectroscopy, and thermal infrared imaging were also used, but far less frequently. In summary, the scope of early urban remote sensing was limited to urban planning and infrastructure development applications and was hindered by the limited availability of imagery. Since the 1950's, there has been a noticeable movement from studying urban infrastructure and morphology, to 
studying the human dimension of urban environments using remote sensing techniques.

\subsection{Recent Urban Remote Sensing, 1971-Present}

The following section covers the more recent period in urban remote sensing, 1971 to present, with an emphasis on the current state of the art. Studies of urban land cover/use, urban structure, urban heat island effects, and change analysis are reviewed. Then, a variety of studies designed to study urban populations are outlined. Finally, the emergence of a diverse group of empirical studies concerned with the social science aspects of urban places is traced.

It should be noted that with the advent of digital imaging and soft-copy photogrammetric techniques, the number, variety, and nature of remote sensing applications have increased tremendously. For example, the commercial availability of high spatial resolution imagery (primarily in panchromatic mode) has led to developments of image processing techniques targeting the improvement of coarse spatial resolution imagery. One way of achieving this is by employing image fusion techniques that preserve spectral detail in coarse resolution imagery and high spatial resolution of panchromatic imagery (Ranchin et al., 2001). Additionally, the complexity and dynamics of urban environments often necessitate the use of multi-sensor, multi-resolution data sets, eventually leading to the use of data compression techniques such as principal component analysis (PCA), spatial filtering, and image transforms in the wavelet domain (Donnay et al., 2001). As a result, a number of image processing and analysis techniques have been tailored for implementation into efficient urban remote sensing analysis, resulting in broader and more diverse applications.

\subsubsection{Land Cover and Land Use}

Studies of urban land cover and land use are the backbone of urban remote sensing. Although the specific goals of The complexities many studies differ, most begin with the of urban environments have led researchers to develop new and varied approaches to studies of urban land cover and land use. identification and classification of the land cover or land use within the urban scene. Due to the many complexities of urban environments researchers have devised new approaches designed to improve classification accuracies. One such approach has been the development of expert systems, which are essentially logic-based systems that allow remotely sensed data to be integrated with ancillary data in an attempt to provide more accurate classification results. Stefanov et al. (2001b) developed an expert system to monitor urban land cover change 
in Phoenix, Arizona. System inputs included Landsat TM imagery, an image derived texture measure and vegetation index, water rights and land use data. A novelty of this research is that it was one of the first applications of such an approach for a semiarid-arid urban environment. The researchers found that improved classification accuracies support the use of an expert system, especially in urban environments with heterogeneous land covers. That same expert system was later modified for use with ASTER data (Stefanov, 2002), and used to study land cover diversity across a number of different urban centers (Netzband and Stefanov, 2003).

Hybrid approaches to urban land use and land cover mapping have also been developed. Lo and Choi (2004) designed a hybrid method using both unsupervised and supervised approaches as well as hard and soft classifications. They used Landsat 7 ETM+ data to study metropolitan Atlanta, Georgia. The authors found that the hybrid approach performed slightly better (compared to the unsupervised clustering approach), and that the supervised fuzzy classification was efficient in low-density urban use areas characterized by mixed pixels.

Recently though, researchers have used sub-pixel methods such as spectral mixture models to quantify and measure the composition of urban land cover (Rashed et al., 2001; Small, 2001; Wu and Murray, 2003). These "soft" approaches to classification are becoming increasingly more popular as researchers attempt to model the heterogeneity that exists within urban environments. Rashed et al. (2001) used spectral mixture analysis (SMA) to derive physical measures of urban land cover that describe the morphological characteristics of the Greater Cairo region. The authors suggest that SMA may be superior to other standard classification methods, especially when used in an urban context. They applied their model to an Indian Remote Sensing multispectral image (IRS-IC LISS-III) of Cairo, Egypt, in an attempt to produce a replicable procedure to analyze the anatomy of cities.

Since urban environments are particularly complex, given the diversity of land cover and land use types, Herold et al. (2004) suggest the use of hyperspectral data as a way to deal with the spectral complexities of urban environments. The authors developed and analyzed a field spectral library in the $350-400 \mathrm{~nm}$ spectral range, consisting of approximately 4,500 individual spectra. They also evaluated the most suitable wavelength for the separation of urban land cover and related them to the spectral bands of two sensor systems, IKONOS and Landsat $\mathrm{ETM}+$. This interesting comparison highlights the spectral limitation of most current sensor systems - often the optimal bands lie outside or near the edge of the sensors' spectral range. The results of their study indicate the future potential of hyperspectral data for urban analysis. 


\subsubsection{Urban Form and Structure}

Image processing approaches such as image texture measures and spatial pattern analysis have been applied to the study of urban form and structure. Application of image texture analysis to urban environments is particularly widespread and is well developed as a methodology for improving our understanding of urban places.

A variety of quantitative measures of image texture have been developed with the aim of capturing the underlying spatial structure of the urban scene (Brivio and Zilioli, 2001). Barnsley et al (2001) modeled image texture using standard gray level co-occurrence matrices and provided a good review of image texture methods. High within class variability is a common characteristic of urban regions, particularly in urban-rural transition areas (Pesaresi and Bianchin, 2001).

Researchers have often incorporated image texture measures as an additional input layer to the classification process. This has proved particularly useful in urban remote sensing studies. Shaban and Dikshit (2001) used both texture and spectral classification of SPOT images in their study of Lucknow city, India. They found that the incorporation of texture measures, such as the grey level difference histogram (GLDH) and the sum and difference histogram (SADH), significantly increased classification accuracies. Other researchers have also utilized texture measures as an additional input in the classification process (Kontoes et al., 2000; Stefanov et al., 2001a, Orun, 2004).

Kontoes et al. (2000), integrated texture and spatial context into kernel based classifiers to study land use in the city of Athens. High spatial resolution $(5 \mathrm{~m})$ IRS-1C imagery was used. The authors emphasize the important relationship between kernel size and classification accuracy. Using this method, residential classes in the urban area were classified with a high level of accuracy. Stefanov et al. (2001a) showed that texture measures of variance generated from ASTER imagery could be used to study levels of urbanization in cities (i.e. decentralized, centralized).

Spatial pattern analysis is another approach for analyzing image structure by quantifying the spatial arrangement of image brightness components in an image. This can be accomplished using geo-statistical techniques such as semi-variogram analysis as discussed by Brivio and Zilioli (2001).

Researchers have begun to use spatial (landscape) metrics to examine the structure and pattern of urban environments. Herold et al. (2003) used spatial metrics as part of an integrated model to study the spatial and temporal aspects of urban development in the region of Santa Barbara, California. Some problems associated with spatial metrics were noted, such as the sensitivity of the results to changes in spatial 
resolution or extent. Overall though, the authors found spatial metrics to be an important tool that provides additional information about urban structure and pattern.

\subsubsection{Urban Heat Island Effect}

Urban areas can alter their surrounding climate, due in part to the removal of natural vegetation for urban development and the heterogeneity of urban surface features. As such, urban areas can be significantly warmer than non-urbanized areas, this is known as the urban heat island effect.

The urban heat island effect in Guangzhou, China was studied using multidate Landsat TM imagery (Weng, 2003). The spatial variability in surface radiant temperatures was modeled using transects across the urban area. In addition, fractal analysis was utilized as a method to improve the understanding of the thermal behavior of land cover types and patterns. The authors found that two major heat islands existed, yet the extent of the heat islands varied by season. Over time urban development had increased the spatial variability of radiant temperatures in the region. Data on urban surface temperatures taken from Landsat TM imagery that details the spatial variability of the urban heat island effect have also been integrated into quality of life studies (Lo, 1997).

Methods for deriving urban surface radiant temperatures can be quite complex and a number of different approaches can be taken. Quattrochi and Goel (1995) examined both spatial and temporal scale issues of thermal infrared data, and discussed the factors affecting the process of deriving urban surface temperatures. A number of different sensors, not elaborated on here, have been utilized for the study of urban heat island effects such as TIMS (Quattrochi and Ridd, 1994), AVHRR (Gallo et al., 1995), and ATLAS (Quattrochi et al., 2000).

Voogt and Oke (2003) provide a detailed, up to date review of thermal remote sensing of urban climates. They discuss the relatively slow pace of development in this field, summarize the literature on this topic, and list important urban studies that have applied thermal remote sensing.

\subsubsection{Change Analysis}

Studies of urban change over both space and time have become increasingly important as the world's urban population continues to grow. Remotely sensed data are especially suited to providing details of urban land cover change over a variety of scales both spatially and temporally (Ward et al. 2000).

The anatomy of spatial growth and change in Bangkok, Thailand was studied using Landsat 5-TM imagery (Babu Madhavan et al., 2001). The researchers utilized two classification methods, a traditional maximum 
likelihood supervised classification and a biophysical, vegetationimpervious-soil (VIS) approach based on the model developed by Ridd (1995). Ward et al. (2000) utilized multidate Landsat TM imagery to model changes in urban composition as an indicator of the dynamics of growth in a rapidly urbanizing area near Queensland, Australia.

Information on changes in land use are an important input to the urban planning process. Turker and Asik (2002) used multidate Landsat TM imagery to detect both the size and nature of land use changes in Ankara, Turkey. They were then able to demonstrate significant rural-tourban conversion in urban fringe areas. Hoffine Wilson et al. (2003) developed a geo-spatial model to quantify and map urban growth. The model, which utilized Landsat TM imagery, provided researchers with a powerful visual and quantitative analysis of both the type and extent of urban sprawl.

Other methods have been developed with the aim of improving change analysis studies. Westmoreland and Stow (1992) incorporated ancillary data with fused SPOT panchromatic and Landsat TM multispectral images in an integrated image processing/GIS to aid in the visual interpretation of changed land use. A framework was developed to aid in the interactive identification of land-use categories in land-use updates through the simultaneous display of digital image data with the vector land-use data to be updated.

In a study of urban expansion and flood risk assessment in Nouakchott, Mauritania, Wu et al. (2003) utilized image fusion techniques to model change. SPOT panchromatic imagery was fused with multispectral imagery for two study dates, 1995 and 1999, followed by vectorization. Ancillary demographic data were then added (in a GIS), and the researchers mapped areas of urban expansion and flood risk.

Studies of change can also be undertaken with the goal of assessing within class change. Rashed et al. (in press), undertook a multi-temporal study of change analysis between the years 1987 and 1996 in the city of Cairo, Egypt. The authors sought to emphasize land cover change within classes (rather than between classes) in an attempt to model urban morphology.

\subsubsection{Urban Population Studies}

Humans continuously modify their living environment and remotely

Both day and night-time imagery have been used to study urban populations. sensed imagery can be used to study urban populations through the characteristics of their environments. Through a number of methods, both day and night-time remotely sensed imagery can be 
used to estimate population size, density, and distribution.

Urban populations have been studied using image-derived variables from color infrared photography, Landsat MSS and TM, and SPOT imagery, all captured under daylight conditions. Ogrosky (1975) suggested the usefulness of satellite imagery for estimating urban populations. He showed how imagery derived variables such as urban area boundaries, transportation links, urban area of nearest largest neighborhood (NLN), and highway distance to the NLN, were strongly associated with population count data taken from the census. Other researchers have applied similar models to study population density using remotely sensed imagery (Lindgren, 1971; Lo and Welch, 1977).

lisaka and Hegedus (1982) utilized a regression analysis model to test the relationship between population density and the reflected electromagnetic energy of their study area, Tokyo, Japan using Landsat MSS data. A similar method using SPOT imagery was developed by Lo (1995) and applied in Kowloon, Hong Kong, to estimate both population and dwelling units. Overall estimates were reasonable at the macro level, yet individual estimates of population and dwelling units were not reliable in areas of very high population density characterized by multiuse buildings. Harvey (2002) explored various refinements to the previously described methods and achieved reasonably accurate results while noting that accuracy was generally greater in suburban areas and that high densities were more often under-estimated while low densities over-estimated.

More recently researchers have integrated remotely sensed imagery with census (or survey) data to estimate populations. Chen (2002) developed a method to correlate areal census data with residential densities. The residential densities were classified from remotely sensed data using TM bands 1-5 and 7, together with a texture measure (derived from the TM imagery). Disaggregating areal census data via this approach was successful in a suburban environment.

Urban places have also been examined extensively through the use of night-time satellite imagery. Human activity and levels of development associated with urban places can be assessed using night-time imagery, allowing researchers not only to detect urban places, but also to monitor urban growth and to compare urban places via their relative light levels.

Night-time imagery from the DMSP OLS has proven extremely useful in the evaluation of urban areas in a variety of ways at both the global and regional scales. Although, available in analog format since 1972, the availability of OLS imagery in digital format beginning in 1992 spurred its use as a source for analyzing the dynamics and temporal aspects of urban places. 
Sutton et al. (2001) used DMSP OLS imagery to estimate both the urban population of every nation in the world, as well as national and global populations. Their quantitative analysis of human populations was based on methodology established by Tobler (1969) and Nordbeck (1965). This type of analysis is particularly useful considering the large number of 'data poor' nations, places where either recent or reliable estimates of population size and distribution are not available.

Night-time lights imagery have also been useful as a data source for generating urban indicators that may enable better understanding of urban populations than demographic data alone. Lo (2002) used zones of radiance extracted from OLS data and a triangulated irregular network (TIN). Surface area and volume were also generated and input into an allometric growth model used to estimate urban indicators for 35 cities in China. This method proved to be very accurate when used to estimate total non-agricultural population, a commonly used demographic measure of urbanization.

Gallo et al. (2004) also used DMSP OLS data of the United States to study changes in levels of night-time light emitted between 1992/93 and the year 2000. In concert with the night-time lights data, the researchers also computed a time-integrated Normalized Difference Vegetation Index (TINDVI) for the same period across time and space. Those places where increased levels of emitted night-lights occurred also showed a decrease in the TINDVI. The authors suggest that areas of land cover change and increased night-light brightness have likely undergone increased urbanization.

There have been some technical challenges to using the DMSP OLS data. Concern about the overestimation of urban extent and shift in locational accuracy is due in part to the difficulty in selecting light thresholds. Pixel saturation, due to the 6-bit radiometric resolution of the DMSP OLS data, has also been a problem (Sutton, 1997). Finally, an obvious limitation is the low spatial resolution of the imagery. The use of DMSP OLS data has been successful at the global, regional and city scale; however their effectiveness has not been shown at any finer scale.

\subsubsection{Social Science Applications}

Many forms of social science data are increasingly being georeferenced,

Many social science data sets are now routinely georeferenced. distributed, and archived. This opens up new avenues for the exploration of these data and allows for new ways of analyzing them, when combined with remotely sensed data. The vast array of remotely sensed data now available to researchers allows for the analysis of the physical

environment in ways not always possible through other methodologies. 
Remote sensing can serve as a link between the physical environment and the social lives of urban residents, and perhaps lead to improved understanding of the relationship between the built environment and numerous demographic and social processes. Many of these social science applications frequently rely on empirical modeling approaches.

With empirical models, the intention is to establish a relationship between a variable of interest and variables estimated from remotely sensed data. While most biophysical variables can be estimated from remotely sensed data alone, socio-economic variables require the use of additional data sources that provide supplemental information about variables affecting the model parameters. Standard textbooks on the subject of modeling cover the theory and techniques in greater depth. Here, it is important to emphasize that empirical modeling (such as estimation of human population densities from remotely sensed images) may be useful in determining if a relationship exists, but lacks the explanatory component, i.e. does not reveal why the relationship exists. This characteristic along with the difficulties in transferring an empirical model to other cities or populations for instance, limits empirical models from use in predictive modeling where it is essential to understand the causality component of variables involved in the processes of interest.

Social science applications in the empirical model form have been applied specifically to the study of urban places and populations. As many regions of the world are rapidly becoming more urbanized, the analysis of urban areas along with a greater understanding of quality of life is crucial to the understanding of what the future may hold for urban populations (Vlahov and Galea, 2003). A number of recent studies, some described here, have integrated remote sensing data with urban population, quality of life, health, poverty, crime, and other similar socioeconomic data types. These studies do much to promote the utility and interdisciplinary attractiveness of remotely sensed data.

In a study that shows the utility of remote sensing for health and quality of life related research, Lo (1998) integrated environmental variables derived from satellite imagery, such as land use/land cover, NDVI, and surface temperature, with census data on population density, house value, education, and income. Using this combined data set he assessed quality of life in Athens-Clarke County, Georgia and found that remotely sensed data adds value to the study of urban quality of life.

Another study in the socio-economic realm sought to show the utility of remote sensing and GIS to identify potential low-income housing sites (Thomson and Hardin, 2000). The authors used TM imagery of Bangkok, Thailand, to identify land cover and land use classes using a two-stage hybrid classification technique. Through a set of criteria (i.e. flood risk, density) input into a GIS, they were able to identify land area most 
suitable for low-income housing. The authors note that planners need to consider more than just the socio-economic factors of possible housing sites; they must also consider the physical characteristics of the sites.

Other types of health and well-being applications have also been explored. Fugate (2003) utilized quantitative measures of the physical environment derived from remotely sensed data to investigate the role of environmental context in relation to child health in Cairo, Egypt. In a study of intra-urban variability of fertility in Cairo, Egypt, Weeks et al. (2004) used imagery from the IRS sensor and image processing methods such as spectral mixture analysis to obtain quantitative measures of environmental context, such as the amount of green space and the percentage of impervious materials in a urban neighborhood. They were then able to characterize in a quantitative manner the built and natural environment in each neighborhood. This is a good example of how, through the use of remotely sensed imagery, we can extract measures or details about the physical environment that can then be linked to the socio-economic environment.

Public health applications of remote sensing show much promise, and as such are worth reviewing here for their utility in quantifying features of the landscape and how they may affect health. This can of course be applied to both urban and rural places. The use of remote sensing has shown most success in the identification and monitoring of habitats for vectors of disease spread. Through the use of remotely sensed imagery the presence of specific vegetative cover, water, specific temperatures ranges, and elevation can all be used to characterize potential vector habitats. Tatem and Hay (2004) provide an up to date review of remote sensing and health in relation to urban environments, and explore the potential of remote sensing for malaria research in an urban context. Considering the pace of urbanization, especially in developing countries, the public health community must refocus some of its efforts towards health issues in urban places.

\section{Chapter Summary}

In an attempt to synthesize the development and growth of urban remote sensing, this chapter presents the most prominent aspects of the evolution of imaging sensor systems and urban remote sensing applications over the past fifty years. Many other aspects of urban remote sensing have only been addressed briefly here, yet are presented in more detail in other chapters devoted to spectral and temporal properties of urban environments. The paper by Jensen and Cowen (1999) provides a comprehensive review of the spatial, spectral, and 
temporal characteristics of urban attributes and remote sensing systems. The paper covers data availability and requirements for a number of the most common earlier remote sensing applications such as land use and land cover classification, building and cadastral infrastructure mapping and planning, and utility and transportation system analysis.

Further developments within the field of remote sensing and the allied mapping sciences of GIS and cartography, including the increasingly available commercial, high spatial resolution imagery, should enhance the ability to learn and understand more aspects of urban places and populations. Besides some challenges and inconclusive results, the first attempts have already been made to link the physical and social attributes of urban environments. Morphing physical remote sensing with social sciences appears to be the current trend in studies of urban environments. Here, we have attempted to emphasize that the joint evolution of remote sensing technologies and urban remote sensing applications is what keeps this research theme alive.

\section{LEARNING ACTIVITIES}

- In the context of this chapter, we have used the term technological advances as a collective definition for all of the following: (a) technical specifications of imaging systems, (b) increased availability of remotely sensed imagery, and (c) improvements in techniques for image processing and analysis. Do you agree with our definition? Further, do you agree with the statement: "Technological advances in imaging sensor capabilities have contributed to the increased breadth and depth of urban remote sensing applications, resulting in rich, interdisciplinary topics that come under the umbrella of urban remote sensing"? Support your answer with examples.

- Outline the evolution of satellite imaging systems in terms of their spatial, radiometric, spectral, and temporal resolutions. What factors do researchers need to consider when selecting the appropriate imagery for their studies? What type of requirement tradeoffs might need to be made? 
- Prioritizing the four major technical characteristics of imaging systems (spatial, radiometric, spectral, and temporal resolutions) has proven to be difficult. Generally, there has not been unanimous agreement on prioritization due to the variable role of image resolutions in specific urban remote sensing applications. Consider the importance of resolutions discussed in section 7.2.5 for several remote sensing imaging systems that you envision using for a specific urban remote sensing problem of interest. Attempt to prioritize their importance from the perspective of a particular study. Support your answer by explaining the immediate objectives and the image processing and analysis steps involved in your example study.

- List several reasons that could lead to the use of data compression techniques. Considering the examples of data compression techniques provided in the beginning of section 7.3.2, provide some examples of how each data compression technique might be used in specific urban remote sensing applications.

- How have researchers adapted their methods to better model the complexities of urban environments?

- One common characteristic of many urban remote sensing applications discussed in section 7.3.2.6 is their empirical analysis nature. What does it take for empirical studies to evolve into scientific hypothesis-based research? Provide an explanation bearing a particular sample study in mind.

- Explain how interdisciplinary approaches to the study of urban environments have contributed to the evolution of urban remote sensing?

\section{References}

Babu Madhavan, B., S. Kubo, N. Kurisaki, and T. V. L. N. Sivakumar, 2001. Appraising the anatomy and spatial growth of the Bangkok Metropolitan area using a vegetationimpervious-soil model through remote sensing. International Journal of Remote Sensing, v. 22 , pp. 789-806.

Barnsley, M. J., L. Moller-Jensen, and S. L. Barr, 2001. Inferring urban land use by spatial and structural pattern recognition, in J. P. Donnay, M. J. Barnsley, and P. A. Longley, eds., Remote Sensing and Urban Analysis: London, England, Taylor \& Francis.

Brivio, P. A., and E. Zilioli, 2001. Urban pattern characterization through geostatistical analysis of satellite images, in J. P. Donnay, M. J. Barnsley, and P. A. Longley, eds., Remote Sensing and Urban Analysis: London, England, Taylor \& Francis.

Chardon, R. E., and E. L. Schwertz, 1972. An annotated bibliography of remote sensing applied to urban areas, 1950 - 1971: Baton Rouge, School of Geoscience Louisiana State University, $39 \mathrm{p}$.

Chen, D. and D. Stow, 2002. The effect of training strategies on supervised classification at different spatial resolutions. Photogrammetric Engineering and Remote Sensing, v68, pp. 1155-1161. 
Chen, D., D. Stow, and P. Gong, in press. Examining the effect of spatial resolution on classification accuracy: An urban environmental case, International Journal of Remote Sensing.

Chen, K., 2002. An approach to linking remotely sensed data and areal census data. International Journal of Remote Sensing, v. 23, pp. 37-48.

Dickinson, L. C., Boselly, S. E., and Burgmann, W. W., 1974. Defense Meterological Satellite Program user's guide, Air Weather Service (MAC), US Air Force.

Donnay, J. P., Barnsley, M. J., and Longley, P. A. (eds)., 2001. Remote Sensing and Urban Analysis. Taylor \& Francis, New York, pp. 268.

Fugate, D., 2003. Environmental context and health: An intra-urban level analysis in Cairo, Egypt. M.A. thesis, San Diego State University, San Diego, Ca, 89 p.

Gallo, K. P., C. D. Elvidge, L. Yang, and C. Reed, 2004. Trends in night-time city lights and vegetation indices associated with urbanization within the conterminous USA. International Journal of Remote Sensing, v. 25, pp. 2003-2007.

Gallo, K. P., J. D. Tarpley, A. L. McNab, and T. R. Karl, 1995. Assessment of urban heat islands: A satellite perspective. Atmospheric Research 37, pp. 37-43.

Harvey, J. T., 2002. Estimating census district populations from satellite imagery: some approaches and limitations: International Journal of Remote Sensing, v. 23, pp. 2071.

Herold, M., N. C. Goldstein, and K. C. Clarke, 2003. The spatiotemporal form of urban growth: measurement, analysis and modeling. Remote Sensing of Environment, v. 86, pp. 286-302.

Herold, M., D. A. Roberts, M. E. Gardner, and P. E. Dennison, 2004. Spectrometry for urban area remote sensing - Development and analysis of a spectral library from 350 to 2400 $\mathrm{nm}$. Remote Sensing of Environment, v. 91, pp. 304-319.

Hoffine Wilson, E., J. D. Hurd, D. L. Civco, M. P. Prisloe, and C. Arnold, 2003. Development of a geospatial model to quantify, describe and map urban growth. Remote Sensing of Environment, v. 86, pp. 273-285.

lisaka, J., and E. Hegedus, 1982. Population estimation from Landsat imagery. Remote Sensing of Environment, v. 12, pp. 259-272.

Jensen, J. R., 1996. Introductory Digital Image Processing. Prentice-Hall, Upper Saddle River, NJ, pp. 318.

Jensen, J. R. and D. C. Cowen, 1999. Remote sensing of urban/suburban infrastructure and socio-economic attributes. Photogrammetric Engineering and Remote Sensing, v. 65, pp. 611-622.

Kontoes, C. C., V. Raptis, M. Lautner, and R. Oberstadler, 2000. The potential of kernal classification techniques for land use mapping in urban areas using $5 \mathrm{~m}$ spatial resolution IRS-1C imagery. International Journal of Remote Sensing, v. 21, pp. 3145-3151.

Lindgren, D. T., 1971. Dwelling unit estimation with color-IR photos. Photogrammetric Engineering, v. 37, pp. 373-377.

Lo, C. P., 1995. Automated population and dwelling unit estimation from high-resolution satellite images: a GIS approach. International Journal of Remote Sensing, v. 16, pp. 1734.

Lo, C. P., 1998. Application of Landsat TM data for quality of life assessment in an urban environment. Computers, Environment, and Urban Systems, v. 21, pp. 259-276.

Lo, C. P., 2002. Urban indicators of China from radiance-calibrated digital DMSP-OLS nighttime images. Annals of the Association of American Geographers, v. 92, pp. 225240.

Lo, C. P., and J. Choi, 2004. A hybrid approach to urban land use/cover mapping using Landsat 7 Enhanced Thematic Mapper Plus (ETM+) images. International Journal of Remote Sensing, v. 25, pp. 2687-2700.

Lo, C. P. and B. J. Faber, 1997. Integration of Landsat Thematic Mapper and census data for quality of life assessment. Remote Sensing of Environment, 62, pp. 143-157.

Lo, C. P., and R. Welch, 1977. Chinese urban population estimates. Annals of the Association of American Geographers, v. 67, pp. 246-253. 
Netzband, M., and W.L. Stefanov, 2003. Assessment of urban spatial variation using ASTER data. The International Archives of the Photogrammetry, Remote Sensing, and Spatial Information Sciences, 34 (7/W9), pp. 138-143.

Nordbeck, S., 1965. The law of allometric growth: Michigan Inter-University Community of Mathematical Geographers, Paper 7.

Ogrosky, C., 1975. Population estimates from satellite imagery. Photogrammetric Engineering and Remote Sensing, v. 41, pp. 707-712.

Orun, A. B., 2004. Automated identification of man-made textural features on satellite imagery by bayesian networks. Photogrammetric Engineering and Remote Sensing, v. 70, pp. 211-216.

Pesaresi, M. and A. Bianchin, 2001. Recognizing settlement structure using mathematical morphology and image texture. In: J. P. Donnay, M.J. Barnsley and P.A. Longley, editors, Remote Sensing and Urban Analysis. Taylor \& Francis, London, England.

Quattrochi, D. A., and N. S. Goel, 1995. Spatial and temporal scaling of thermal remote sensing data. Remote Sensing Review, 12, pp. 255-286.

Quattrochi, D. A., J. C. Luvall, D. L. Rickman, M. G. Estes Jr, C. A. Laymon, and B. F. Howell, 2000. A decision support information system for urban landscape management using thermal infrared data. Photogrammetric Engineering and Remote Sensing, 66, pp. 1195-1207.

Quattrochi, D. A. and M. K. Ridd, 1994. Measurement and analysis of thermal energy responses from discrete urban surfaces using remote sensing data. International Journal of Remote Sensing, 15, pp. 1991-2022.

Ranchin, T., L. Wald, and M. Mangolini, 2001. Improving the spatial resolution of remotelysensed images by sensor fusion: A general solution using the ARSIS method, in J. P. Donnay, M. J. Barnsley, and P. A. Longley, editors, Remote Sensing and Urban Analysis: Taylor and Francis, London, England.

Rao, R. S. and A. M. Cook, 2004. New Eye in the Sky: RESOURCESAT-1, Imaging Notes, Winter 2004, pp. 9-30.

Rashed, T., J. R. Weeks, M. S. Gadalla, and A. G. Hill, 2001. Revealing the anatomy of cities through spectral mixture analysis of multispectral satellite imagery: A case study of the Greater Cairo region, Egypt. Geocarto International, v. 16, pp. 5-15.

Rashed, T., J. R. Weeks, D. Stow, and D. Fugate, in press. Measuring temporal compositions of urban morphology through spectral mixture analysis: Toward a soft approach to change analysis in crowded cities. International Journal of Remote Sensing.

Ridd, M. K., 1995. Exploring a V-I-S (vegetation-impervious surface-soil) model for urban ecosystem analysis through remote sensing: Comparative anatomy for cities. International Journal of Remote Sensing, v. 16, pp. 2165-2185.

Schowengerdt, R. A., 1997. Remote Sensing - Models and Methods for Image Processing. Academic Press, pp. 522.

Shaban, M. A., and O. Dikshit, 2001. Improvement of classification in urban areas by the use of textural features: the case stidy of Lucknow city, Uttar Pradesh. International Journal of Remote Sensing, v. 22, pp. 565-593.

Small, C., 2001. Estimation of urban vegetation abundance by spectral mixture analysis. International Journal of Remote Sensing, v22, pp.1305-1334.

Stefanov, W. L., 2002. Assessment of landscape fragmentation associated with urban centers using ASTER data. American Geophysical Union EOS Transactions 83 (47), Abstract B61C-0739.

Stefanov, W. L., P.R. Christensen, and M.S. Ramsey, 2001a. Remote sensing of urban ecology at regional and global scales: Results from the Central Arizona-Phoenix LTER site and ASTER Urban Environmental Monitoring program, Regensburger Geographische Schriften 35, pp. 313-321 (on supplemental CD ROM).

Stefanov, W. E., M. S. Ramsey, and P. R. Christensen, 2001b. Monitoring urban land cover change: An expert system approach to land cover classification of semiarid to arid regions. Remote Sensing of Environment, v. 77, pp. 173-185.

Sutton, P., 1997. Modeling population density with night-time satellite imagery and GIS. Computers, Environment, and Urban Systems, v. 21, pp. 227-244. 
Sutton, P., D. Roberts, C. Elvidge, and K. Baugh, 2001. Census from Heaven: an estimate of the global human population using night-time satellite imagery. International Journal of Remote Sensing, v. 22, pp. 3061-3076.

Tatem, A. J., and S. I. Hay, 2004. Measuring urbanization pattern and extent for Malaria research: A review of remote sensing approaches. Journal of Urban Health, v. 81, pp. 363-376.

Thomson, C. N., and P. Hardin, 2000. Remote sensing/GIS integration to identify potential low-income housing sites. Cities, v. 17, pp. 97-109.

Tobler, W., 1969. Satellite confirmation of settlement size coefficients. Area, v. 1, pp. 30-34.

Turker, M. and O. Asik, 2002. Detecting land use changes at the urban fringe from remotely sensed images in Ankara, Turkey. Geocarto International, 17, pp. 45-50.

Vlahov, D., and S. Galea, 2003. Urban health: a new discipline. Lancet, v. 362, pp. 10911093.

Voogt, J. A. and T. R. Oke, 2003. Thermal remote sensing of urban climates. Remote Sensing of Environment, 86, pp. 370-384.

Ward, D., S. R. Phinn, and A. T. Murray, 2000. Monitoring growth in rapidly urbanizing areas using remotely sensed data. Professional Geographer, v. 52, pp. 371-385.

Weeks, J. R., A. Getis, A. G. Hill, M. S. Gadalla, and T. Rashed, 2004. The fertility transition in Egypt: Intra-urban patterns in Cairo. Annals of the Association of American Geographers, v. 94, pp. 74-93.

Welch, R., 1982. Spatial resolution requirements for urban studies. International Journal of Remote Sensing, v3, pp. 139-146.

Weng, Q., 2003. Fractal analyis of satellite-detected urban heat island effect. Photogrammetric Engineering and Remote Sensing, 69, pp. 555-566.

Westmoreland, S., and D. A. Stow, 1992. Category identification of changed land-use polygons in an integrated image processing/geographic information system. Photogrammetric Engineering and Remote Sensing, v. 58, pp. 1593-1599.

$\mathrm{Wu}, \mathrm{C}$. and Murray, A.T., 2003. Estimating impervious surface distribution by spectral mixture analysis. Remote Sensing of Environment, v84, pp. 493-505.

Wu, W., M. F. Courel, and J. Le Rhun, 2003. Application of remote sensing to the urban expansion analysis for Nouakchott, Mauritania. Geocarto International, v. 18, pp. 17-24. 